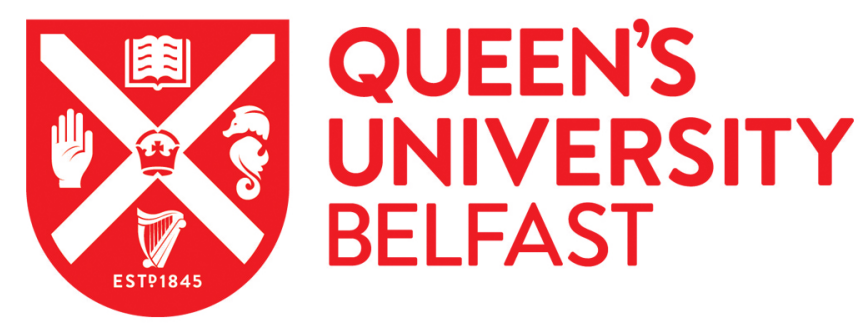

\title{
Comparative allometric variation in intertidal chitons (Polyplacophora: Chitonidae)
}

Ibanez, C. M., Sepúlveda, R. D., \& Sigwart, J. D. (2017). Comparative allometric variation in intertidal chitons (Polyplacophora: Chitonidae). Zoomorphology. https://doi.org/10.1007/s00435-017-0387-2

\author{
Published in: \\ Zoomorphology
}

Document Version:

Peer reviewed version

Queen's University Belfast - Research Portal:

Link to publication record in Queen's University Belfast Research Portal

Publisher rights

( ) Springer-Verlag GmbH Germany, part of Springer Nature 2017. This work is made available online in accordance with the publisher's policies. Please refer to any applicable terms of use of the publisher.

\section{General rights}

Copyright for the publications made accessible via the Queen's University Belfast Research Portal is retained by the author(s) and / or other copyright owners and it is a condition of accessing these publications that users recognise and abide by the legal requirements associated with these rights.

Take down policy

The Research Portal is Queen's institutional repository that provides access to Queen's research output. Every effort has been made to ensure that content in the Research Portal does not infringe any person's rights, or applicable UK laws. If you discover content in the Research Portal that you believe breaches copyright or violates any law, please contact openaccess@qub.ac.uk. 


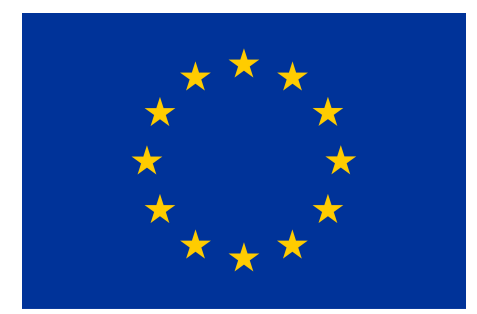

This project has received funding from the European Union's Horizon 2020 research and innovation programme under the Marie Skłodowska-Curie grant agreement No H2020-MSCAIF-2014-655661.

This copy of the accepted manuscript is provided to enable dissemination through Open Access to the scientific data; the version of record is that provided by the publishers. 
$5{ }^{1}$ Departamento de Ecología y Biodiversidad, Facultad de Ecología y Recursos Naturales, 6 Universidad Andrés Bello, Santiago, Chile.

$7 \quad{ }^{2}$ Instituto de Ciencias Ambientales y Evolutivas, Facultad de Ciencias, Universidad Austral 8 de Chile, Valdivia, Chile.

$9{ }^{3}$ Research Centre: South American Research Group on Coastal Ecosystems (SARCE), 10 Caracas, Venezuela.

$11{ }^{4}$ University of California Berkeley, Berkeley, California, USA.

$12{ }^{5}$ Queen's University Belfast, Marine Laboratory, Portaferry, N Ireland.

14 *Corresponding author: Christian M. Ibáñez, ORCID iD: 0000-0002-7390-2617, 15 Telephone: +56227703890, e-mail: ibanez.christian@gmail.com

17 Abstract Allometry involves the study of the relationship between size and shape of an 18 individual, and in particular, the manner in which shape depends on size. Animals with 19 multi-element skeletons may have differing growth allometries in different parts of the 20 body. Chitons, for example, have eight overlapping shell plates or valves of three distinct 21 types: head (one plate), intermediate (six plates), and tail (one plate). The overall chiton

22 body is ellipsoidal and different species differ in their eccentricity. The aim of this study 23 was to examine overall allometry in size and shape over adult ontogeny, and how these 24 patterns vary among four closely-related species of intertidal chitons from Southeastern 
1 Pacific Ocean. For each specimen $(n=407)$, measurements were taken of total body length

2 and the exposed anterio-posterior lengths of the eight shell plates. Multivariate allometry

3 was evaluated by means of a Principal Component Analysis for each species separately,

4 and for the total. The results showed differential allometric growth of specific skeletal

5 elements, which varied among species; however, there was no clear evidence for specific

6 differentiable growth stages. The overall trend among the combined species was for weakly

7 positive allometry of shell plate widths, but isometric growth of total length and width;

8 thus, the lateral proportion of the animal occupied by shell increases over growth and

9 conversely "thinner looking" girdles may be generally indicative of older animals.

11 Keywords: Allometry, shell shape, growth, polyplacophorans, morphometry, Southeastern 12 Pacific.

\section{Introduction}

15 The form of an organism corresponds to the integration of size and shape. By definition, 16 shape consists of those aspects of form that remain when size is removed (Mosimann 1970;

17 Bookstein 1991). Intra-specific morphological variation among natural populations has

18 been frequently observed and well documented, particularly, in shelled gastropods (e.g.

19 Rolán et al. 2004; Conde-Padín et al. 2007; Sepúlveda and Ibáñez 2012; Avaca et al. 2013).

20 Morphological variation within species is determined, in first instance, by the variation in

21 body size of the individuals that compose a population (Huxley 1932; Kemp and Bertness

22 1984). This association between shape and size implies quantitative scaling relationships

23 that can explain or even determine some processes within a population (Gayon 2000;

24 Economo et al. 2005). 
Allometry deals with variation of traits associated with variation of the overall size

2 of the organisms. The traits can be the size of parts, their shape, or physiological,

3 ecological, and behavioural characteristics, but the range of traits considered differs among

4 the various concepts of allometry (Klingenberg 1998). Growth is often accompanied by

5 changes in proportion as well as in size, which is known as the phenomenon of relative or

6 allometric growth (i.e. shape changes during growth). Isometric growth refers to structures

7 that vary proportionally with overall body size (Klingenberg 1996; 1998). Allometric

8 growth occurs when a structure does not co-vary in linear proportion with total body size

9 (Huxley 1932; Gayon 2000). Basic descriptions of allometry can provide a foundation for

10 understanding the potential predictive power of specific shape variables (Dryden and

11 Mardia 1998; Klingenberg 1998).

12 Chitons are a marine molluscan group belonging to class Polyplacophora, which are

13 relatively morphologically constrained among extant taxa (Sirenko 2006; Sigwart 2009).

14 These animals have a biphasic life cycle, with a dispersing trochophore larva that settles to

15 the benthos where grows the ventral foot and mineralises eight shell plates (Eernisse 2007).

16 Chitons usually attach to hard substrates with their muscular foot, which is protected by

17 their characteristic articulating eight-part shell armour. The first (anterior: head) and the last

18 (posterior: tail) plates are approximately semi-circular, their breadths are usually smaller

19 than the intermediate plates in keeping with the overall oval body form (Schwabe 2010).

20 The six intermediate plates are similar in shape, though shell plate II (immediately behind

21 the head) is anterio-posteriorly elongated compared to the others, and in many species (e.g.,

22 Lepidochitona cinereus, Tonicella marmorea), there is a clear difference in widths among

23 plates in a single animal (Baxter 1982; Baxter and Jones 1986; Connors et al. 2012). These

24 plates provide protection while still allowing some degree of flexibility during locomotion 
1 over uneven and rough surfaces, as well as when rolling defensively into a ball-like

2 conformation when dislodged from a surface (Connors et al. 2012; Sigwart et al. 2015).

3 This complex multi-element armature is a combination of hard and soft aspects, with shell

4 plates surrounded by a flexible girdle, and there is potential inter-specific variability in

5 growth of all the various components (Baxter and Jones 1986; Avila-Poveda and Abadia-

6 Chanona 2013).

7 Particularly, allometry of body shape and size in chitons has been described as a 8 tool to examine plasticity, and as a potential source of characters to differentiate between 9 similar species during their adult ontogeny (Baxter 1982; Baxter and Jones 1986), and to 10 determine relationships of size allometry in the length-weight relationship (e.g., Chiton 11 albolineatus) to relate differential growth rates of the different components of the chiton 12 body (Baxter \& Jones 1986; Flores-Campaña et al. 2012).

13 Herein, we explored the allometric and morphological variation of shell plates of 14 four common intertidal polyplacophoran species from the same family Chitonidae, but 15 covering multiple genera. These species have differing but largely overlapping ranges in 16 the shallow southeast Pacific (Araya and Araya 2015). The four chiton species selected 17 belong to the same taxonomic family (Chitonidae), yet the conformation and size of shell 18 plates are very different: Acanthopleura echinata (Barnes, 1824) and Enoplochiton niger 19 (Barnes, 1824) have larger size and narrower plates, while Chiton granosus Frembly, 1827 20 and Tonicia elegans Frembly, 1827 have smaller size and wider plates. Following these 21 observations of shape, we used whole animals in dorsal view (flat, intact animals with shell 22 plates in place) to test whether the relative proportions of shell plates shifts as animals get 23 larger, and how these patterns vary among species. The comparative allometry of overall 24 body shape in these four species during ontogeny provides a strong basis to establish a 
1 potential generalised allometric relationship between shape variables and body size in

2 chitons and contributes to understanding of growth laws in marine invertebrates.

$4 \quad$ Materials and methods

$5 \quad$ Study areas and sample collection

6 A total of 407 adult specimens $(\geq 10 \mathrm{~mm})$ belonging to four species of intertidal chitons

7 were obtained through original fieldwork between 2011 to 2016 and identified as 8 Acanthopleura echinata, Chiton granosus, Enoplochiton niger, and Tonicia elegans (Figure

9 1). The inclusion of "adult specimens" is referred to the exclusion of larvae and extremely

10 small specimens $(<10 \mathrm{~mm})$, and is not related to their sexual maturity. Size at maturity in

11 chitons has been reported for species of the genus Chiton from Mexico, Peru and Chile, and

12 these studies suggested that chitons mature at small body size ( $<30 \mathrm{~mm}$ : Sotil 2004; Avila-

13 Poveda and Abadia-Chanona 2013; Vélez-Arellano et al. 2014; Brito 2017). Animals were

14 collected on intertidal rocky shores and subtidal shallow waters until five meters depth at

1514 locations along the Southeastern Pacific Ocean within their overlapping geographical

16 distribution, which ranges between $4^{\circ} \mathrm{S}$ and $42^{\circ} \mathrm{S}$ latitude (Araya and Araya 2015) over

17 more than 4,500 km of coastline (Table 1, Figure 2A). Conspecific individuals from all

18 localities were combined for morphometric analyses, aimed to include all shape and size

19 variation along the gradient among all localities. All specimens measured in this study were

20 deposited at the Museo Nacional de Historia Natural, Chile (MNHNCL).

\section{Allometric analysis}

23 To analyse the morphological variation of each species of chiton, the following 12 24 distance variables were measured on ethanol preserved specimens through a digital calliper 
1 (precision: $\pm 1 \mathrm{~mm}$ ): total length (TL), total width (TW), length of plate I and plate VIII (the

2 terminal shell plates), and widths of each shell plate (I to VIII) (Figure 2B). We made a

3 correction of body length by standardized width of each plate dividing each plate width by

4 total length to compare shell plates standardized width across species. To avoid

5 morphometric bias or skew, we used only flattened specimens and did not take any

6 measurements from curled specimens. All statistical analyses were performed in R (ver.

7 3.1.2, R Core Team 2014), and specific commands are noted below to avoid possible 8 ambiguity about interpretation of results.

9 First, a bivariate approach was used to determine the standard allometric coefficient

10 for each variable with respect to total length in each species. The slope coefficient and $90 \%$

11 and $95 \%$ confidence intervals of the standard allometric equation $\log (x)=\log (a)+b \log (\mathrm{TL})$

12 (Huxley 1932), were calculated via ordinary least squares regression. These calculations

13 determine whether the ontogeny of individual measurements is isometric $(b=1)$ with

14 respect to body length. When a $95 \%$ confidence interval for the allometric coefficient does

15 not overlap over the null hypothesis ( $b=1$, isometric growth), then the slope of the variable

16 indicates allometric growth $(b \neq 1)$. Moreover, when the allometric growth is defined, then

17 we may infer hypo-allometric growth or negative allometry $(b<1)$ or hyper-allometric 18 growth or positive allometry $(b>1)$ over ontogeny for that variable.

19 Second, a multivariate approach was employed to explore potential shifts in shape-

20 space over ontogeny within each species, using Principal Component Analysis (PCA). In a

21 dataset comprising multiple ontogenetic sets (species, or variables), the first component

22 (PC1) summarises changes in size, while second (PC2) and later components reflect

23 variation in shape trajectories (Shea 1985). Therefore, in a PCA combining data from

24 multiple ontogenetic stages, any shifts in growth patterns would be indicated by changes in 
1 the relationship of PC2 to PC1 or to total length (i.e. asymmetric distribution, or clear

2 breaks in the distribution of plotted data; Nikolioudakis et al. 2010).

3 The original measurement data for 12 variables were log-transformed and subjected

4 to a PCA for each species separately, specifying a variance-covariance matrix (R command

5 prcomp). The distribution of PC2 values calculated for each single-species' dataset was

6 visually inspected in relation to individual values for PC1 and specimen size (TL) to

7 identify potential breaks or shifts in allometry that would indicate differential growth 8 stages.

9 Third, the multivariate analysis was extended to a simultaneous PCA for the four 10 species, to test whether shape could be used to differentiate species. As before, log11 transformed data were subjected to PCA. Loading (rotation) values for PC1 for each 12 variable were compared to the expected value, by calculating a $95 \%$ confidence interval on 1310,000 bootstrap replicates (boot.ci, using type "basic"). When the confidence interval 14 includes the expected variable factor loading value $(1 / 12)^{0.5}$ for an element in an analysis of

1512 component variables, this would indicate isometry of that variable with respect to 16 overall shape (Shea 1985).

\section{Results}

19 The size range (TL) of chitons measured and used in this study varied between 24 and 141

$20 \mathrm{~mm}$ (mean $76.9 \pm 32.9$ S.D.) for Acanthopleura echinata, between 14 and $79 \mathrm{~mm}$ (mean

$2144.0 \pm 5.0$ S.D.) for Chiton granosus, between 44 and $110 \mathrm{~mm}$ (mean $75.9 \pm 18.8$ S.D.) for

22 Enoplochiton niger, and between 10 and $58 \mathrm{~mm}$ (mean $31.2 \pm 11.1$ S.D.) for Tonicia

23 elegans (Figure 1 and 2B). In all four species, as in all typical chitons, the terminal shell 
1 plates were the narrowest, and the central shell plates (IV-VI) were wider, though the

2 widths of various features generally differed among species (Figure 3).

3 Bivariate comparisons of each individual component to overall body length

4 indicated varying patterns of growth, which were not consistent among taxa but 5 corresponded to observed patterns in morphology (Table 2). In particular, the posterior

6 parts of the armature of E. niger and A. echinata had significantly positive allometry, thus

7 the widths of posterior shell plates get wider more rapidly as overall body length increases;

8 while the most shell plates in $T$. elegans showed significantly negative allometry relative to

9 body length, indicating that the overall body size increases more rapidly than the widths of

10 the shell plates. A. echinata and C. granosus showed isometric growth in the anterior and

11 posterior shell plates, respectively (Table 2 ).

12 In multivariate analyses, first principal component (PC1) in species-specific

13 analyses accounted for more than $92 \%$ of variation. The signs of the PC1 loadings were 14 consistent within each species (either all positive, or all negative), indicating that PC1 15 distributes specimens according to length. The second principal component (PC2) reflects 16 changes in shape; this accounted for between $0.9 \%$ (A. echinata) to a maximum of $4 \%$ (E. 17 niger) of the variation. Comparison of $\mathrm{PC} 2$ values with body length (TL) and PC1 values 18 showed a symmetrical uncorrelated distribution with no evidence of any ontogenetic shifts.

19 The other components (PC3-PC12) have little variation $(<1 \%)$.

20 Multi-species PCA also recovered a first principal component accounting for $95.3 \%$

21 of variability. The PC1 loadings for all 12 variables were positive and of similar values,

22 indicating this component is a length axis reflecting scaling of features with body length

23 more than shape change; several features were positively allometric, although others

24 showed isometry (Table 2). The second component PC2 contributes to the separation of 
1 species according to shape, especially $T$. elegans and A. echinata (Figure 4). The factors

2 with relatively larger loadings for PC2 indicate which are potentially more relevant to

3 shape variation: these features are total length (0.42), total width $(0.24)$, and the length of

4 shell plate VIII (-0.86). For PC3 larger loadings are total width (-0.43), and the length of 5 shell plate I $(0.84)$.

7 Discussion

8 This study gives us strong evidence that shape differences and allometry even among 9 closely related, ecologically similar taxa have species-specific patterns that were previously 10 unappreciated. These results are concordant to Klingenberg $(1996 ; 2010)$, who indicated a

11 multidimensional inherent growth even when simple shapes vary in many different ways.

12 Quantitatively, the features that contribute most to shape variation (i.e., total length, total

13 width, and the length of shell plates I and VIII) all increase isometrically on average (Table $142)$.

15 These intertidal chitons showed different types of allometry among their shell 16 plates, a pattern previously reported in other species (Saad 1997). There is weak evidence 17 that the terminal plates have a less positively allometric growth than intermediate plates: 18 the widths of terminal plates have lower values for the allometry coefficients, compared to 19 intermediate plates in the multi-species PCA (Table 2), and the lengths of the terminal 20 plates grow isometrically with respect to total size. These differences may be a 21 consequence of their terminal location; in the tail plate, growth is holoperipheral and both 22 terminal plates superficially are based on a more elliptic shape.

23 The shape of chitons is more or less oval in outline, but among the 1000 living 24 species this presents a wide variation from broad oval to worm like (vermiform) body shape 
1 (Schwabe 2010). Shape allometry, changes in the outline shape during adult growth, varies

2 among species and can potentially vary in separate populations (Emam and Ismail 1993).

3 This variation is in part related to niche specification, both in specific adaptations of overall

4 body size and in terms of shell construction and material strength (Sigwart et al. 2015). Acanthopleura echinata has a size-segregating vertical distribution, in that the

6 largest individuals of the species are found relatively lower (Otaíza and Santelices 1985).

7 Our sampling nonetheless covered the whole vertical range of that species. Among the 8 species studied, three are in the exposed intertidal but one species is found in lower 9 intertidal to shallow subtidal waters (T. elegans). Tonicia spp. generally lack complex shell 10 sculpture and the features of the girdle perinotum are often so diminutive that the dorsal 11 girdle surface seems to be nude. This suggests both morphological separation and 12 ecological separation correlated to a distinct allometric pattern in this species that differs 13 from the other three.

14 In this study, we found differences in shape and size for the four species. These 15 species of chitons live at the intertidal zone often exposed to heavy surf or under boulders 16 in the shallow subtidal waters (Araya and Araya 2015). The largest species (A. echinata and 17 E. niger) showed lower variability in the standardized widths of shell plates, while the 18 relatively smaller species (C. granosus and T. elegans) showed higher variability in the 19 standardized width shell plates. These differences could be consequence of a phylogenetic 20 separation, or may be a by-product of shallower niche specialisation.

21 It is not presently clear whether there is any ontogenetic shift in mechanical 22 conformation of the chiton armature due to different life stages and their corresponding 23 inner organization related to processes such as gonadal ontogenesis, gonad development 24 stages, sexual differentiation, and onset of the first sexual maturity (Avila-Poveda and 
1 Abadia-Chanona 2013). While we did not find any evidence for specific allometric shifts in

2 any of the specific variables, it is clear that there is a strong interaction of size and shape.

3 Ontogenetic variation on shell shape has been found in many other molluscs,

4 including intertidal snails showing a strong allometry (e.g., Kemp and Bertness 1984;

5 Hollander et al. 2006; Avaca et al. 2013). Allometry can differ among species and reflect

6 evolutionary change in growth patterns related to ecological or physiological factors (Gould

7 2002; Klingenberg 2010). In chitons, allometric growth could be related to their

8 extraordinary morphology; articulated shell plates allow the chitons to fit within crevices to

9 avoid predators, or (for intertidal species) to use rocks or under-boulders as refuge to avoid

10 the sunlight (Otaíza and Santelices 1985; Flores-Campaña et al. 2012). Apparently, chiton

11 allometry, comparatively to other molluscs (i.e., gastropods and bivalves), could be the

12 result of a combination of shell plate shape, differential growth rates, and environmental

13 influences (Baxter 1982; Baxter and Jones 1986; Flores-Campaña et al. 2012).

14 While chitons appear superficially similar, straightforward morphometry can

15 indicate clear differences among even closely related species. Different aspects of the

16 multielement chiton armature experience differential growth allometries, which apparently

17 experience a continuous shift over post-settlement life. These points provide specific data

18 that may be relevant to field identification of growth stages; the negative allometry of plate

19 widths in T. elegans means that older specimens would have apparently relatively wider

20 girdles, while the opposite is true in E. niger. We examined allometry in four common

21 species; chitons are morphologically constrained, yet these species are clearly different in

22 shape and size. Not only to they have a different shell plate morphometric pattern, but their

23 allometry, the acquisition of a distinctive shape over ontogeny, is also variable. Within the

24 chiton scleritome, individual elements experience independent but coordinated growth 
1 trajectories. Expanding further on this approach promises new insights to the functioning of

2 chiton armour during growth.

\section{Acknowledgements}

5 This study was financially supported by FONDECYT \#1130266 grant "Evolutionary 6 biogeography of the Southeastern Pacific polyplacophorans" to C.M. Ibáñez. We are

7 grateful to F. Alfonso, A. Cifuentes, S. Curaz, A. Fabres, A. Navarrete, M.C. Pardo-

8 Gandarillas, V. Sanhueza, J. Salazar, C. Tobar and G. Torretti for their assistance in field 9 and laboratory work.

\section{Ethical standards}

12 This research was approved by the Universidad Andres Bello ethical committee and the

13 Chilean government through FONDECYT. The manuscript has not been submitted to more

14 than one journal for simultaneous consideration nor has it been published previously.

16 Conflict of interest

17 The authors declare that they have no conflict of interest with any other projects, 18 researchers or organizations, commercial or otherwise. 


\section{$1 \quad$ References}

3 Araya JF, Araya ME (2015) The shallow-water chitons (Mollusca, Polyplacophora) of

4 Caldera, Region of Atacama, northern Chile. Zoosyst Evol 91:45-58

5 Avaca MS, Narvarte M, Martín P, van der Molen S (2013) Shell shape variation in the

$6 \quad$ Nassariid Buccinanops globulosus in northern Patagonia. Helgol Mar Res 67:567-577

7 Avila-Poveda OH, Abadia-Chanona QY (2013) Emergence, development, and maturity of

8 the gonad of two species of chitons "sea cockroach" (Mollusca: Polyplacophora)

9 through the early life stages. PLoS ONE 8: e69785

10 Baxter JM (1982) Allometric and morphological variations of whole animal and valve

11 dimensions in the chiton Lepidochitona cinereus (L.) (Mollusca: Polyplacophora). J

$12 \quad$ Moll St 48:275-282.

13 Baxter JM, Jones AM (1986) Allometric and morphological characteristics of Tonicella

14 marmorea (Fabricius, 1780) populations (Mollusca: Polyplacophora: Ischnochitonidae).

$15 \quad$ Zool J Linn Soc 88:167-177

16 Bookstein FL (1991) Morphometric tools for landmark data. Cambridge: Cambridge

17 University Press, pp 435

18 Brito MJ (2017). Ecología reproductiva en tres especies de Chiton Linnaeus, 1758

19 (Mollusca: Polyplacophora) en Coquimbo, Chile. Master Degree Thesis. Universidad

20 Católica de la Santísima Concepción, Chile. 76 pp.

21 Conde-Padín P, Grahame JW, Rolán-Alvarez E (2007) Detecting shape differences in

22 species of the Littorina saxatilis complex by morphometric analysis. J Moll St 73:147$23 \quad 154$ 
1 Connors MJ, Ehrlich H, Hog M, Godeffroy C, Araya S, Kallai I, Gazit D, Boyce M, Ortiz

2 C (2012) Three-dimensional structure of the shell plate assembly of the chiton Tonicella

3 marmorea and its biomechanical consequences. J Struct Biol 177:314-328

4 Dryden IL, Mardia KV (1998) Statistical shape analysis. New York: John Wiley and Sons

$5 \quad$ Ltd., pp 347

6 Economo EP, Kerkhoff AJ, Enquist BJ (2005) Allometric growth, life-history invariants

$7 \quad$ and population energetic. Ecol Lett 8:353-360

8 Eernisse DJ (2007) Chitons. In: Denny MW and Gaines SD (eds). Encyclopedia of

9 tidepools and rocky shores. Berkeley: University of California Press, pp 127-133

10 Emam WM, Ismail NS (1993) Intraspecific variation in the morphometrics of

11 Acanthopleura hadrloni (Mollusca: Polyplacophora) from the Arabian Gulf and Gulf of

12 Oman. Zool Middle East 8:45-52

13 Flores-Campaña LM, Arzola-González JF, De León-Herrera R (2012) Body size structure, 14 biometric relationships and density of Chiton albolineatus (Mollusca: Polyplacophora)

15 on the intertidal rocky zone of three islands of Mazatlan Bay, SE of the Gulf of

16 California. Revista de Biología Marina y Oceanografía 47:203-211

17 Gayon J (2000) History of the concept of allometry. Amer Zool 40:748-758

18 Gould SJ (2002) The structure of evolutionary theory. London: Harvard University Press, $19 \quad$ pp 1433

20 Hollander J, Adams DC, Johannesson K (2006) Evolution of adaptation through allometric 21 shifts in a marine snail. Evolution 60:2490-2497

22 Huxley JS (1932) Problems of relative growth. London: Methuen, Co. LTD., pp 276

23 Kemp P, Bertness M (1984) Snail shape and growth rates: Evidence for plastic shell 24 allometry in Littorina littorea. Proc Natl Acad Sci USA 81:811-813 
1 Klingenberg CP (1996) Multivariate allometry. In: Marcus LF, Corti M, Loy A, Naylor

2 GJP, Slice DE, editors. Advances in Morphometrics. New York: Plenum Press, pp 23349

4 Klingenberg CP (1998) Heterochrony and allometry: the analysis of evolutionary change in 5 ontogeny. Biol Rev 73:79-123

6 Klingenberg CP (2010) Evolution and development of shape: integrating quantitative 7 approaches. Nat Rev Genet 11:623-635

8 Mosimann JE (1970) Size allometry: size and shape variables with characterizations of the 9 lognormal and generalized gamma distributions. J Am Stat Ass 65:930-945

10 Nikolioudakis N, Koumoundouros G, Kiparissis S, Somarakis S (2010) Defining length-at11 metamorphosis in fishes: a multi-character approach. Mar Biol 157:991-1001

12 Otaíza RD, Santelices B (1985) Vertical distribution of chitons (Mollusca: Polyplacophora)

13 in the rocky intertidal zone of central Chile. J Exp Mar Biol Ecol 86:229-240

14 R Core Team (2014) R: A language and environment for statistical computing. R 15 Foundation for Statistical Computing, Vienna, Austria. http://www.R-project.org/

16 Rolán E, Guerra-Varela J, Colson I, Hughes RN, Rolán-Alvarez E (2004) Morphological 17 and genetic analysis of two sympatric morphs of the dogwhelk Nucella lapillus 18 (Gastropoda: Muricidae) from Galicia (Northwestern Spain). J Moll Stud 70:179-85

19 Saad AEA (1997) Morphometric studies on the rock chiton Acanthopleura spiniger 20 (Mollusca: Polyplacophora) from the northwestern region of the Red Sea. Indian J Mar $21 \quad$ Sci $26: 49-52$

22 Schwabe E (2010) Illustrated summary of chiton terminology (Mollusca, Polyplacophora). 23 Spixiana 33:171-194 
1 Shea BT (1985) Bivariate and multivariate growth allometry: statistical and biological

2 considerations. J Zool Lond 206:367-390

3 Sepúlveda RD, Ibáñez CM (2012) Clinal variation in the shell morphology of intertidal

4 snail Acanthina monodon in the Southeastern Pacific Ocean. Mar Biol Res 8:363-372

5 Sigwart JD (2009) Morphological cladistic analysis as a model for character evaluation in

6 primitive living chitons (Polyplacophora, Lepidopleurina). Am Malacol Bull 27:95-104

7 Sigwart JD, Green PA, Crofts SB (2015) Functional morphology in chitons (Mollusca,

8 Polyplacophora): influences of environment and ocean acidification. Mar Biol

$9 \quad 162: 2257-2264$

10 Sirenko B (2006) A new outlook on the system of chitons (Mollusca: Polyplacophora).

11 Venus 65:27-49

12 Sotil GE (2004) Variación estacional de la madurez gonadal y oogénesis de Chiton

13 cumingsii Frembly, 1827 de Bahía Ancón, Lima Perú. Biology Thesis. Universidad

14 Nacional Mayor de San Marcos. Lima, Perú. 63 pp.

15 Vélez-Arellano N, Shibayama M, Ortiz-Ordóñez E, Silva-Olivares A, Arellano-Martínez

16 M, García-Domínguez F (2014) Histological description of oogenesis in Chiton

17 virgulatus (Mollusca: Polyplacophora). International Journal of Morphology 32:608$18 \quad 613$ 
1 Fig. 1 Pictures of dorsal view (shell plates I to VIII oriented from left to right) of the whole

2 animal for A) Acanthopleura echinata, scale bar $=20 \mathrm{~mm}$, B) Chiton granosus, scale bar $=$

$310 \mathrm{~mm}, \mathrm{C})$ Enoplochiton niger, scale bar $=20 \mathrm{~mm}$ and D) Tonicia elegans scale bar $=20$

$4 \mathrm{~mm}$

6 Fig. 2 Map of sampling sites along the Southeastern Pacific coast (A), and dorsal view of a

7 generalized chiton (B) showing the main morphological measurements (white lines) used in

8 this study. I-VIII = shell plates from anterior to posterior

10 Fig. 3 Standardized width ( $\mathrm{mm}$ ) of shell plates I to VIII for the four species of chitons used

11 in this study: A) Acanthopleura echinata, B) Chiton granosus, C) Enoplochiton niger, and

12 D) Tonicia elegans. The box-plots indicate the median, $25^{\text {th }}$ and $75^{\text {th }}$ (boxes) percentiles, $1310^{\text {th }}$ and $90^{\text {th }}$ (whiskers) percentiles, and outliers of the size distribution of chitons

15 Fig. 4 Shape differences in four species of chitons, resulting from combined principal 16 components analysis. The second component (PC2, responsible for shape) is related to total 17 body size represented by body length $(\mathrm{mm})$. The four species studied are shown in different 18 colours 